Revue bibliographique pour le domaine irano-aryen

\title{
Zohreh Zehbari. "The Borazjan Monuments: A Synthesis of Past and Recent Works"
}

\section{Sébastien Gondet}

\section{(2) OpenEdition}

1 Journals

\section{Édition électronique}

URL : https://journals.openedition.org/abstractairanica/52503

DOI : 10.4000/abstractairanica.52503

ISSN : 1961-960X

Éditeur :

CNRS (UMR 7528 Mondes iraniens et indiens), Éditions de l'IFRI

Référence électronique

Sébastien Gondet, "Zohreh Zehbari. "The Borazjan Monuments: A Synthesis of Past and Recent Works" », Abstracta Iranica [En ligne], Volume 42-43 | 2021, document 31, mis en ligne le 15 avril 2021 consulté le 13 décembre 2022. URL : http://journals.openedition.org/abstractairanica/52503 ; DOI : https://doi.org/10.4000/abstractairanica.52503

Ce document a été généré automatiquement le 13 décembre 2022.

Tous droits réservés 


\title{
Zohreh Zehbari. "The Borazjan Monuments: A Synthesis of Past and Recent Works"
}

\author{
Sébastien Gondet
}

\section{RÉFÉRENCE}

Zohreh Zehbari. “The Borazjan Monuments: A Synthesis of Past and Recent Works". [en ligne] ARTA 2020.002, 2020, 52p. http://www.achemenet.com/pdf/arta/

ARTA_2020_002_Zehbari.pdf

1 Diverses opérations archéologiques depuis les années 1970 ainsi que, plus récemment, des analyses épigraphiques des Archives des Fortifications de Persépolis ont démontré l'importance de la région de Borazjan à l'époque achéménide. L'investissement du pouvoir royal dans l'aménagement de cette région côtière au sud du Fars, située actuellement dans la province de Boushehr, est parfaitement démontré par la présence de trois constructions monumentales, séparées de plusieurs kilomètres, à salle centrale hypostyle. Elles présentent de nombreuses similitudes architecturales avec les constructions royales de Pasargades, surtout, et de Persépolis. Néanmoins, jusqu'à présent, les données archéologiques sur les sites de Borazjan (parfois appelé Dashtestan) ont été majoritairement publiées en persan sous forme d'articles ou d'une monographie de E. Yaghma'i parue récemment, tous peu diffusés. Le présent article en anglais se propose de synthétiser de manière ordonnée et normalisée les informations contenues dans ces différentes publications et ainsi de les rendre disponibles à un large lectorat. Pour ce faire, l'A. s'appuie sur une bibliographie exhaustive des publications archéologiques traitant de cette région. Chacun des trois bâtiments de Borazjan fait l'objet d'une description précise des vestiges mis au jour. La documentation est très riche, intégrant de nombreuses photographies de terrain prises par l'A. On soulignera également le travail de mise au propre des plans des différents bâtiments ainsi que la production de dessins inédits de plusieurs éléments architecturaux. L'article se conclue 
sur une discussion courte et pertinente concernant la difficile question de la datation de ces monuments que l'A. associe à un projet lancé à l'époque de Cyrus puis achevé par Darius.

2 Cette synthèse rassemble donc une documentation scientifique essentielle pour l'archéologie de l'époque achéménide qui, pour le sud de l'Iran, est donc loin de se limiter aux seuls sites de Pasargades et Persépolis. Néanmoins, se pose désormais la question cruciale de la fonction de ces constructions. Elle ne pourra trouver une réponse qu'en élargissant la documentation archéologique au-delà des seules constructions monumentales. L'A. signale l'amorce, au cours des dernières années, de nouvelles opérations de prospections et de fouilles autour des trois bâtiments. Parallèlement, la question du contexte de ces constructions et de leur organisation spatiale fait plus particulièrement l'objet d'un article récent signé d'Emad Matin (voir le compte rendu de l'article dans ce même numéro).

\section{AUTEURS}

\section{SÉBASTIEN GONDET}

UMR 5133 CNRS-Université de Lyon 